\title{
Immunotherapy for tuberculosis: future prospects
}

This article was published in the following Dove Press journal:

ImmunoTargets and Therapy

20 April 2016

Number of times this article has been viewed

\section{Getahun Abate' \\ Daniel F Hoft ${ }^{1,2}$}

'Department of Internal Medicine, Division of Infectious Diseases, Allergy and Immunology, ${ }^{2}$ Department of Molecular Microbiology and Immunology, Saint Louis University, St. Louis, MO, USA
Correspondence: Getahun Abate Department of Internal Medicine, Division of Infectious Diseases, Allergy and Immunology, Saint Louis University, Doisy Research Center, 8th floor, I 100 S. Grand Blvd, St. Louis, MO 63104, USA Tel +l 3l49775500

Email abateg@slu.edu

Daniel F Hoft

Department of Internal Medicine, Division of Infectious Diseases, Allergy and Immunology, Saint Louis University, Doisy Research Center, 8th floor, II 00 S. Grand Blvd, St. Louis, MO 63104, USA

Tel + I 3 |4 9775500

Fax +I 314 77I 3816

Email hoftdf@slu.edu
Abstract: Tuberculosis (TB) is still a major global health problem. A third of the world's population is infected with Mycobacterium tuberculosis. Only $\sim 10 \%$ of infected individuals develop TB but there are 9 million TB cases with 1.5 million deaths annually. The standard prophylactic treatment regimens for latent TB infection take 3-9 months, and new cases of TB require at least 6 months of treatment with multiple drugs. The management of latent TB infection and TB has become more challenging because of the spread of multidrug-resistant and extremely drug-resistant TB. Intensified efforts to find new TB drugs and immunotherapies are needed. Immunotherapies could modulate the immune system in patients with latent TB infection or active disease, enabling better control of $M$. tuberculosis replication. This review describes several types of potential immunotherapies with a focus on those which have been tested in humans.

Keywords: tuberculosis, HDT, immunotherapy, treatment

\section{Introduction}

Tuberculosis (TB) remains a major global public health problem. It is estimated that a third of the world's population is infected with Mycobacterium tuberculosis, the causative agent of TB. There are $\sim 9$ million new cases of TB with 1.5 million deaths annually. ${ }^{1}$ Effective management of TB infection and TB disease requires treatment for at least 6 months. This long treatment duration, coupled with side effects of antiTB drugs, leads to noncompliance resulting in the emergence of drug-resistant TB. Of note, drug-resistant TB is more difficult to treat and significantly increases TB control program costs in high TB endemic countries which have meager resources to begin with. ${ }^{2}$

The World Health Organization reports that several countries have increasing numbers of patients with multidrug-resistant (MDR)-TB, TB caused by M. tuberculosis resistant to at least isoniazid and rifampin. ${ }^{1}$ To make the situation worse, only $20 \%$ of MDR-TB cases were started on appropriate drugs, with $<50 \%$ successful treatment outcome. ${ }^{1}$ Furthermore, the number of MDR-TB cases increased three-fold between 2009 and 2013, mainly due to lack of effective treatment. ${ }^{1}$ In addition, several countries with high prevalence of MDR-TB also suffer from increasing numbers of cases of extensively drug-resistant (XDR)-TB with resistance to isoniazid, rifampin, fluoroquinolones, and aminoglycosides. The treatment of XDR-TB is even more difficult and the outcome unpredictable. ${ }^{1,3}$ Thus, MDR- and XDR-TB are major global public health problems because of the lack of effective treatment, the need for a much longer duration of treatment with second line 
or experimental drugs, and the risk of further spread locally and more widely through immigration. Enhanced efforts to develop new TB therapeutics are urgently needed. The progress in TB drug development has been slow and none of the new drugs tested so far have allowed standard treatment regimen shortening. ${ }^{4}$ Host-directed therapy using immunomodulators is a promising approach which must be explored for better control of TB. This paper reviews the strategies and prospects for TB host-directed therapy immunotherapeutics.

\section{TB latency, host immunity, and M. tuberculosis adaptation}

A better understanding of the nature of host-pathogen interactions is required for the development of immunotherapeutics and to predict the roles of new immunotherapeutics for the management of TB infection and/or disease. It is interesting to note that only $\sim 10 \%$ of $M$. tuberculosis-infected individuals develop TB, but how the majority of infected people control or clear the infection is not fully known. Until recently, it was believed that latent TB infection (LTBI) is a state of mycobacterial dormancy during which the immune system contains virtually all persisting $M$. tuberculosis organisms in a static state within granulomas..$^{5-8}$ An emerging consensus resulting in a paradigm shift in the field maintains that both active TB and LTBI represent dynamic spectra with variable levels of actively replicating and inactive bacilli in different granulomas present in the same infected individual. ${ }^{9,10}$

The immune response can greatly alter the proportions and absolute numbers of actively replicating $M$. tuberculosis in infected persons with concomitant changes in TB disease risks. Because the infection is largely intracellular during paucibacillary LTBI and early reactivation disease, T-cell responses are critically important for protective immunity. CD4+, Th1, and CD8+ T-cell responses are involved in the control of $M$. tuberculosis replication in vivo, as are the cytokines they produce (eg, interferon [IFN- $\gamma]$, tumor necrosis factor [TNF]- $\alpha$, and interlukin [IL]-2). ${ }^{11-13}$ However, these responses alone appear insufficient for bacterial clearance as these T-cell subsets peak during active TB disease and decrease after spontaneous immunologic control without eradication of TB infection. Other immune subsets which tend to accumulate in mucosal tissues, including $\gamma \delta$ T-cells, ${ }^{14,15}$ CD1 restricted T-cells, ${ }^{16}$ and mucosa-associated invariant T-cells, ${ }^{17,18}$ can impact on the levels of protective responses. Figure 1 summarizes protective and counterproductive immune responses in TB.

M. tuberculosis has an incredible capacity to adapt in vivo to a variety of stressful conditions. Pathogenic M. tuberculosis can replicate intracellularly in professional

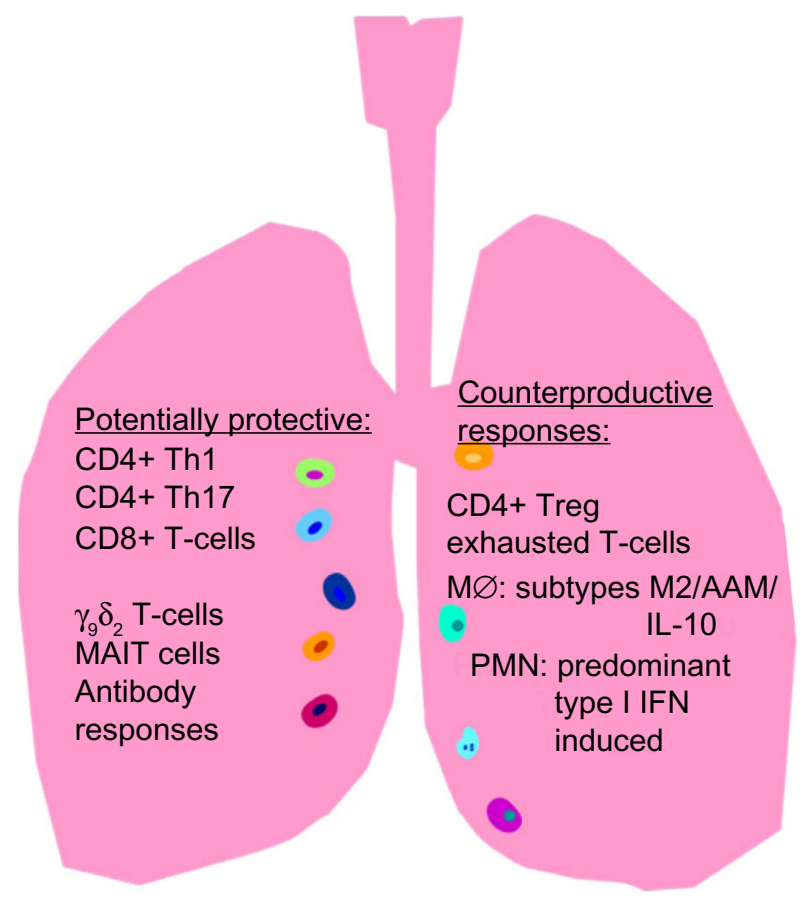

Figure I Tuberculosis (TB)-specific mucosal immune responses are important for protection against latent TB infection (LTBI) reactivation. ThI CD4+ and ThI7 CD4+ T-cells, CD8+ T-cells, $\gamma_{9} \delta_{2}$ T-cells, mucosa-associated invariant T (MAIT) cells, and $s / g A / \lg$ antibody responses are potentially protective against $L T B I$ reactivation which could reduce both TB disease and TB transmission.

Notes: All of these T-cell responses will be considered major targets for immunotherapy in this project because they can recognize intracellular Mycobacterium tuberculosis, the major pathogen reservoir during LTBI. Mucosal antibody responses also could protect against initial infection and transmission, and are being studied in other funded work by our consortium of investigators. CD4+ regulatory T-cell, T-cell exhaustion, alternatively activated macrophages unable to kill intracellular M. tuberculosis and type I IFN-induced polymorphonuclear (PMN) leukocytes can negatively regulate protective immunity in the lung.

mononuclear phagocytes despite numerous mechanisms available to kill intracellular bacilli. The pathogen switches from predominant glucose metabolism when replicating at high rates extracellularly to lipid-based metabolism after uptake in phagosomes of mononuclear phagocytes. The organism thrives in aerobic conditions reaching its highest levels of replication, but can also survive prolonged periods of microaerophilic and even anaerobic conditions. Certain gene sets or regulons are activated intracellularly (eg, DosR) and are thought to be involved in persistence of M. tuberculosis during LTBI. ${ }^{19}$ In addition, other genes associated with reactivation of LTBI have been identified (eg, resuscitationpromoting factors). ${ }^{20-22}$ Although previous data suggest that TB immunity is predominantly directed against antigens produced by replicating $M$. tuberculosis, there is a growing body of evidence that latency-specific antigens are targeted as well. M. tuberculosis mediates multiple immune evasion strategies, including blockade of major histocompatibility complex expression, ${ }^{23-25}$ prevention of phagolysosomal fusion, ${ }^{26-28}$ and inhibition of IFN- $\gamma$ signaling. ${ }^{29-34}$ However, the majority of 
persons infected with TB never develop disease, indicating that the host-pathogen balance can be tipped in favor of the host leading to protective immunity.

Most primary and reactivation TB disease occurs in the lung, and this is the main source of TB transmission. These clinical facts combined with the accumulated knowledge in this area indicate that an optimally effective immunotherapy will need to target mucosal immunity in the lung.

\section{TB immunotherapeutics}

Immunotherapies ideally should modulate the immune system in a way that helps the host control or eliminate M. tuberculosis. Whole mycobacteria, ${ }^{35,36}$ mycobacterial products, ${ }^{37-39}$ cytokines, and drugs have been considered as possible immunomodulators. Table 1 summarizes hostdirected immunotherapeutics which have been tested for the treatment of TB in humans.

\section{M. vaccae and other atypical mycobacteria} There are some controversies on the benefits of Mycobacterium vaccae-based immunotherapy. A single injection enhanced sputum culture conversion at 1 month and led to marked radiographic improvement at 6 months, ${ }^{40}$ but these promising findings were not reproducibly found in other studies. ${ }^{41}$ Nonetheless, meta-analysis of 54 studies using intradermal injection of $M$. vaccae reported that immunotherapy based on M. vaccae could enhance sputum conversion and improve radiographic changes.$^{36}$ Similarly, oral administration of $M$. vaccae enhanced sputum conversion in newly treated TB patients. ${ }^{42}$ Other environmental mycobacteria, such as $M$. indicus pranii, also have shown promising results in animal models. ${ }^{43}$

\section{RUTI ${ }^{\circledR}$}

RUTI is a therapeutic vaccine made of detoxified cellular fragments of M. tuberculosis, delivered in liposomes. It is prepared by mechanically disrupting colonies of M. tuberculosis in phosphate-buffered saline with $4 \%$ TritonX114, heating at $65^{\circ} \mathrm{C}$ for 40 minutes followed by lyophilization and encapsulation in liposomes made of phosphatidyl choline. ${ }^{44}$ In mice and guinea pigs, this therapeutic vaccine was found to have potential for both prophylaxis and immunotherapy. ${ }^{45}$ So far, it has been shown in Phase I and II clinical trials involving healthy volunteers and cases with LTBI that this vaccine is safe and immunogenic..$^{46,47}$

Table I Immunomodulating host-directed therapies for treatment of TB in humans

\begin{tabular}{|c|c|c|c|c|}
\hline Therapeutics & Composition & No. of patients & TB type (outcome) & Refs \\
\hline \multirow[t]{2}{*}{$\begin{array}{l}\text { Mycobacterium } \\
\text { vaccae }\end{array}$} & Killed, intradermal & NA & $\begin{array}{l}\text { Meta-analysis of } 54 \text { studies on newly diagnosed pulmonary TB } \\
\text { (improved sputum conversion and X-ray changes) }\end{array}$ & 36 \\
\hline & Capsule & 41 (two arms) $)^{\Phi}$ & Faster smear conversion & 42 \\
\hline RUTI ${ }^{\circledR}$ & $\begin{array}{l}\text { Detoxified cellular fragments } \\
\text { of Mycobacterium tuberculosis }\end{array}$ & NA & $\begin{array}{l}\text { Phase I and II clinical trials on LTBI cases or healthy volunteers } \\
\text { (immunogenic, reasonable tolerability) }\end{array}$ & 46,47 \\
\hline Autologous MSC & MSC & 30 & MDR or XDR patients ( $2 \mathrm{I} / 30$ with radiologic improvement) & 54 \\
\hline V5 immunitor & Inactivated pooled blood & 55 (two arms) & Re-treatment or proven MDR (higher rate of sputum conversion) & 62 \\
\hline Cytokines and & $\mathrm{IL}-2$ & 50 (two arms) $^{*}$ & MDR-TB patients (better sputum conversion rate) & 73 \\
\hline \multirow[t]{6}{*}{ cytokine inhibitor } & & 23 (three arms) & $\begin{array}{l}\text { MDR-TB patients (decrease AFB smear counts with daily IL-2 } \\
\text { compared to control or pulse IL-2) }\end{array}$ & 71 \\
\hline & & 110 (two arms) $)^{*}$ & New TB patients (significant delays in culture conversion) & 72 \\
\hline & IFN- $\gamma$ & 5 & MDR-TB patients (all smear negative/improved) & 67 \\
\hline & & 7 & MDR-TB cases (no marked microbiologic effect) & 68 \\
\hline & & 6 & MDR-TB cases (no marked microbiologic effect) & 69 \\
\hline & Etanercept & $16^{\S}$ & $\begin{array}{l}\text { HIV-positive TB cases (more rapid culture conversion compared } \\
\text { to historical control) }\end{array}$ & 76 \\
\hline \multirow[t]{5}{*}{ Drugs/compounds } & High dose steroid & $187(\text { two arms })^{\S}$ & HIV-positive TB cases (increased culture conversion at I month) & 79 \\
\hline & Levamisole & $50 \S$ & $\begin{array}{l}\text { Newly diagnosed pulmonary TB patients (improved radiology } \\
\text { but no effect on smear conversion) }\end{array}$ & 82 \\
\hline & Albendazole & 135 (two arms) $^{\S}$ & $\begin{array}{l}\text { New pulmonary TB patients (no effect on clinical, radiologic, and } \\
\text { microbiologic outcome) }\end{array}$ & 83 \\
\hline & Thalidomide & 15 (two arms) ${ }^{*}$ & 9/I5 HIV-positive (clinical improvement) & 102 \\
\hline & & 30 (two arms) $)^{\S}$ & HIV-positive (no clinical difference) & 103 \\
\hline
\end{tabular}

Notes: $\Phi$, different groups including drug-susceptible and drug-resistant cases; $¥$, newly diagnosed pulmonary TB with drug-resistant or MDR-TB as exclusion criteria; $\S$, newly diagnosed pulmonary TB and no drug susceptibility data reported. All TB cases were treated with multidrug-treatment regimen.

Abbreviations: AFB, acid-fast bacilli; HIV, human immunodeficiency virus; IFN, interferon; IL, interleukin; LTBI, latent TB infection; MDR, multidrug-resistant; MSC, mesenchymal stem cells; NA, not applicable; XDR, extensively drug-resistant; TB, tuberculosis. 


\section{DNA vaccines}

A number of DNA vaccines expressing relevant $M$. tuberculosis genes, Hsp65, ESAT-6, and Ag85A, have demonstrated activity in M. tuberculosis-infected mice resulting in a one to three log improvement in M. tuberculosis clearance. ${ }^{48-51}$ More interestingly, an intramuscular DNA vaccine containing Hsp65 and IL-12 genes improved the survival of mice infected with MDR-/XDR-TB. ${ }^{52}$ This particular vaccine uses plasmid cDNA3.1 as a vector expressing Hsp65 and IL-12 incorporated into virus-free envelopes derived from the hemagglutinating virus of Japan. Furthermore, this same DNA vaccine provided a $40 \%$ improvement in survival of M. tuberculosis-infected primates. ${ }^{52}$ These encouraging results suggest that some DNA vaccines may advance into human clinical trials as adjuncts to chemotherapy.

\section{Autologous MSC}

Mesenchymal stem cells (MSC) are progenitor cells constituting a small proportion $(0.01 \%)$ of the bone marrow. ${ }^{53,54} \mathrm{MSC}$ are present in various tissues and organs, including lungs, ${ }^{5,56}$ and are involved in the repair of damaged tissues ${ }^{57,58}$ These cells have been tested for their potential to transform chronic tissue inflammation into an environment capable of inducing robust pathogen-specific immune responses. A recent review describes the interaction of MSC with different cells of the immune system..$^{59}$ Immunomodulatory functions of MSC are mediated by both cell-to-cell contact and release of soluble mediators, such as tumor growth factor (TGF) $-\beta$ and prostaglandin E2. ${ }^{59} \mathrm{~A}$ Phase I study with MSC given to 30 MDR- or XDR-TB patients demonstrated that administration of MSC within 4 weeks of initiation of anti-TB drugs was safe and improved radiological changes. ${ }^{54}$

\section{V5 immunitor}

V5 immunitor, derived from chemical- and heat-inactivated pooled blood from hepatitis B and C virus-positive blood donors, was originally developed for the management of chronic hepatitis B and C. ${ }^{60}$ The exact contents and how this product modulates the immune system remain to be investigated. It has been assumed that some of the blood donors had LTBI and may have circulating M. tuberculosis antigens which may stimulate immune responses ${ }^{61}{ }^{11}$ is also possible that circulating cytokines and/or chemokines in the pooled blood, if they are not inactivated during chemical/heat treatment, enhance T-cell responses to M. tuberculosis antigens in TB patients. Alternatively, other unknown components present could have adjuvant properties. In a Phase I clinical trial, V5 immunitor oral therapy resulted in a markedly better sputum smear conversion at 1 month after initiation of treatment. ${ }^{62,63}$

\section{Cytokines and inhibitors}

M. tuberculosis is an intracellular organism residing mainly in monocytes/macrophages. ${ }^{64}$ This makes cellular immune responses essential for inhibiting intracellular growth and limiting dissemination. M. tuberculosis-specific T-cells produce cytokines and effector molecules, such as perforin, granzymes, and granulysin. ${ }^{65,66}$ Thus, cytokines which enhance the expansion of T-cells and activation/differentiation of antigen presenting cells may help control infection. To this effect, IL-2, IFN- $\gamma$, IL-12, and anti-TNF- $\alpha$ have been tried in small numbers of clinical cases. Although it is difficult to develop definitive conclusions from limited, and in most cases nonrandomized trials, the adjunct use of cytokines or anticytokines has shown some promise. Moreover, host inflammatory response mediated by Th1 cytokines can cause substantial morbidity; therefore, the doses and timing of administration of cytokines may affect the outcome. The adjunct use of IFN- $\gamma$ and IL-12 in some cases of MDR-TB resulted in favorable outcomes. ${ }^{67-69}$ Adjunct aerosolized IFN- $\gamma$ administered at a dose of $500 \mu \mathrm{g}$ three times a week for a total of 4 weeks to five MDR-TB patients was well tolerated and led to smear conversion in all cases. ${ }^{67} \mathrm{~A}$ similar study on six MDR-TB patients using aerosolized IFN- $\gamma$ at a dose of 2 million units three times a week for 6 months showed that all patients reverted back or remained culture positive at the end of treatment. ${ }^{69}$ This may also indicate that the response to IFN- $\gamma$ may vary from patient to patient. In murine TB models, IFN- $\gamma$ administered with intranasal IgA resulted in decreases in M. tuberculosis load in the lungs.$^{70}$ Despite some controversial results regarding the effects of IL-2 tested in new TB cases, ${ }^{71,72}$ intradermal injection of 500,000 IU of IL-2 every other day at the first, third, fifth, and seventh months of drug treatment of 25 MDR-TB patients led to a higher rate of sputum conversion compared to controls receiving only drug-treatment. ${ }^{73}$ IL-2 also enhanced the activities of a pyrophosphate to enhance $\gamma \delta$ T-cell responses and decrease residual M. tuberculosis in the lungs of infected monkeys. ${ }^{74}$ Anti-TNF- $\alpha$ antibodies which are commonly used for treatment of severe rheumatological disorders increase the risk of reactivation of TB. ${ }^{75}$ However, in active TB, anti-TNF- $\alpha$ may enhance culture conversion when combined with $\mathrm{TB}$ multidrug therapy, ${ }^{76}$ probably by delaying the formation of the so-called "persister" forms of tubercle bacilli, leading to increased susceptibility to drug-mediated bactericidal activity. Etanercept, an anti-TNF- $\alpha$, administered at a dose 
of $25 \mathrm{mg}$ subcutaneously twice a week was tested on new pulmonary TB cases who were human immunodeficiency virus (HIV)-positive with a CD4 count $>200 / \mu \mathrm{L}$. The trial included age- and sex-matched controls and showed that sputum culture conversion was slightly more rapid in etanercept treated patients. ${ }^{76}$ The role of etanercept administered in the continuation phase of treatment to shorten the duration of treatment may need to be studied. Similarly, inhibitors of IL- 4 and TGF- $\beta$ were shown to enhance Th1 type immunity and help reduce $M$. tuberculosis bacterial load in the lungs of infected mice. ${ }^{77,78}$

\section{Antibodies}

M. tuberculosis infection induces both celI-mediated and antibody responses. It has been shown that B-cell-deficiency leads to higher bacterial burden and worse outcome following M. tuberculosis infection..$^{79,80}$ Monoclonal antibodies against specific $M$. tuberculosis antigens have shown some conflicting results. ${ }^{81-83}$ This could be partly because of differences in types of antibodies and routes of administration. Using sera from bacillus Calmette-Guerin (BCG)-vaccinated individuals, we had shown that antibodies enhance internalization of mycobacteria by phagocytic cells. ${ }^{84}$ Interestingly, these antibodies from vaccinated individuals significantly increased the ability of macrophages to kill intracellular mycobacteria and led to marked increase in M. tuberculosis-specific cellmediated immunity. ${ }^{84}$ Further works to identify the combinations of monoclonal antibodies, routes, and frequency of administration in animal models may be needed before $M$. tuberculosis-specific antibodies are tested in clinical trials.

\section{Drugs}

Certain host-directed therapies focus on drugs as immunomodulators to facilitate $M$. tuberculosis clearance. Steroids, levamisole, and vitamin D have been tried in humans. High dose steroids have been tried in HIV-positive TB patients. ${ }^{85}$ Although steroid-enhanced culture conversions at 1 month have been observed, the side effects appeared to outweigh the benefits. The antihelminthic drugs, levamisole and albendazole, have been tested in combination with standard anti-TB drugs in new cases of pulmonary TB. Helminth infections induce Th2 predominant immune responses. ${ }^{86}$ Moreover, helminth coinfection leads to Th2 and regulatory T-cell dominant immune responses impairing TB-protective Th1 responses. ${ }^{86,87}$ Therefore, treatment of helminth infections may modulate the immune response, inducing subsets more able to limit the progression of disease. Unfortunately, the results with antihelminthic drugs have not been very encouraging so far. Levamisole given to new TB patients resulted in improvements in radiological findings but no change in smear conversion rate ${ }^{88}$ Recently, a randomized clinical trial with albendazole for 3 days in combination with standard anti-TB drugs in patients with pulmonary TB and helminth coinfection demonstrated no difference in clinical score, smear conversion, and imaging changes compared to placebo. ${ }^{89}$ The roles of nutritional status, degree of immunosuppression from TB disease, and HIV coinfection on the outcomes of the adjunct use of antihelminthic drugs need to be studied further. The use of vitamin D for TB predates TB chemotherapy. Vitamin D activates macrophages via toll-like receptor signaling pathway leading to increased production of mycobactericidal peptides, cathelicidin, and its active form LL-37. ${ }^{90}$ Unfortunately, clinical trials with vitamin D supplements have resulted in controversial results. ${ }^{91}$

Other drugs targeting tyrosine kinases and phagosomal acidification, autophagy, hydrolysis of cyclic adenosine monophosphate and cyclic guanosine monophosphate, inflammation, angiogenesis, and epidermal growth factor receptor have shown encouraging results in murine $\mathrm{TB}$ models. Imatinib is an inhibitor of Abelson tyrosine kinase used mainly in the treatment of Philadelphia chromosomepositive chronic myelogenous leukemia. Because Abelson tyrosine kinase is important for the regulation of lysosomal $\mathrm{pH}$ in macrophages, inhibition of its function decreases lysosomal $\mathrm{pH}$ and enhances the ability of macrophages to kill M. tuberculosis..$^{92}$ Furthermore, the use of imatinib alone or in combination with rifampin has been found to decrease the bacterial load in the lungs of M. tuberculosis-infected mice. ${ }^{93}$ This drug appears to be generally safe although there are case reports of interstitial lung disease associated with imatinib and nilotinib, a second generation tyrosine kinase inhibitor. $^{94,95}$ Metformin, an antidiabetic agent, is an autophagy inducer via activation of adenosine monophosphate-activated protein kinase. Metformin inhibited the intracellular growth of $M$. tuberculosis, restricted disease immunopathology, and enhanced the efficacy of conventional anti-TB drugs in mice. ${ }^{96}$ Moreover, in a retrospective study of TB patients with diabetes mellitus, it was found that patients who were on metformin had fewer pulmonary cavities and significantly better survival. ${ }^{96}$ Similarly, other autophagy inducers, such as statins (simvastatin, rosuvastatin) and gefitinib (an inhibitor of epidermal growth factor receptor), were shown to decrease bacterial load in M. tuberculosis-infected mice. ${ }^{97,98}$ The safety and efficacy of imatinib, metformin, and statin in murine $\mathrm{TB}$ studies make them potential candidates for human clinical trials. 
Treatment with the anti-inflammatory drug, ibuprofen, resulted in decreases in the size and number of lung lesions, decreases in bacillary load, and improvement in survival of M. tuberculosis-infected C3HeB/FeJ mice. ${ }^{99}$ Ibuprofen also enhances the anti-TB activities of the anti-TB drug, pyrazinamide, during the initial phase of treatment. ${ }^{100}$ Similarly, other drugs which may reduce inflammation, prostaglandin E2 and zileuton (a leukotriene inhibitor), decrease lung colony forming units and improve survival in mice infected with $M$. tuberculosis. ${ }^{101}$ Phosphodiesterase inhibitors, such as sildenafil and cilostazole, likely by interfering with the breakdown of cyclic adenosine monophosphate and cyclic guanosine monophosphate and interfering with downstream signaling events, shorten the duration of TB treatment in mice. ${ }^{102} \mathrm{CC}-3052$, a new phosphodiesterase-4 inhibitor and thalidomide analogue, decreased lung pathology and bacterial load significantly when combined with isoniazid in a rabbit TB model. ${ }^{103}$

\section{Knowledge gaps and novel strategies}

Most of the studies on immunotherapy so far have focused on TB treatment. This may help shorten standard treatments or improve the management of MDR/XDR-TB. Because a third of the population is infected with $M$. tuberculosis, immunotherapeutics which enhance the eradication of latent infection could have a major impact on TB control. The effects of new immunotherapeutics/vaccines on the progression or reactivation of LTBI in humans remain to be studied.

Because most cases of TB are pulmonary, immunotherapeutics may give a better outcome if they modulate mucosal immune responses. Lessons from TB vaccine studies should be applied to new immunotherapeutics. Numerous animal and human studies demonstrate that in general, mucosal vaccinations induce more effective mucosal immunity than systemic vaccinations. With regard to TB mucosal immunity, murine studies with BCG and new TB vaccines clearly demonstrated that mucosal vaccination via the intranasal route induced superior protection against subsequent aerosol challenges with M. tuberculosis. ${ }^{104-106}$ It was further shown that mucosal T-cells present in the lung airways of mice postvaccination were the best predictors of protective immunity, and when transferred intratracheally these cells alone could protect against $M$. tuberculosis aerosolized challenges. ${ }^{105,107}$ Therefore, approaches which facilitate the recruitment of relevant $M$. tuberculosis-specific T-cells to the lung and limit nonspecific inflammation should be studied. Host-directed therapy potentially could provide exciting new avenues for the management of LTBI and TB disease, providing hope of shortening standard LTBI and TB treatments as well as improving treatment of MDR/XDR-TB.

\section{Disclosure}

The authors report no conflicts of interest in this work.

\section{References}

1. World Health Organization. Global Tuberculosis Report. Geneva: World Health Organization; 2014.

2. Sinanovic E, Ramma L, Vassall A, et al. Impact of reduced hospitalisation on the cost of treatment for drug-resistant tuberculosis in South Africa. Int J Tuberc Lung Dis. 2015;19(2):172-178.

3. Pietersen E, Ignatius E, Streicher EM, et al. Long-term outcomes of patients with extensively drug-resistant tuberculosis in South Africa: a cohort study. Lancet. 2014;383(9924):1230-1239.

4. Working Group on New TB Drugs. Drug Pipeline. Available from: http://www.newtbdrugs.org/pipeline.php. Accessed January 25, 2016.

5. Corper HJ, Cohn ML. The viability and virulence of old cultures of tubercle bacilli; studies on 30-year-old broth cultures maintained at 37 degrees C. Tubercle. 1951;32(11):232-237.

6. Wayne LG. Dormancy of Mycobacterium tuberculosis and latency of disease. Eur J Clin Microbiol Infect Dis. 1994;13(11):908-914.

7. Wayne LG, Hayes LG. An in vitro model for sequential study of shiftdown of Mycobacterium tuberculosis through two stages of nonreplicating persistence. Infect Immun.1996;64(6):2062-2069.

8. Wayne LG. In Vitro model of hypoxically induced nonreplicating persistence of Mycobacterium tuberculosis. Methods Mol Med. 2001;54:247-269

9. Barry CE 3rd, Boshoff HI, Dartois V, et al. The spectrum of latent tuberculosis: rethinking the biology and intervention strategies. Nat Rev Microbiol. 2009;7(12):845-855.

10. Lin PL, Flynn JL. Understanding latent tuberculosis: a moving target. J Immunol. 2010;185(1):15-22.

11. Brighenti S, Andersson J. Induction and regulation of CD8+ cytolytic $\mathrm{T}$ cells in human tuberculosis and HIV infection. Biochem Biophys Res Commun. 2010;396(1):50-57.

12. Seder RA, Darrah PA, Roederer M. T-cell quality in memory and protection: implications for vaccine design. Nat Rev Immunol. 2008;8(4):247-258.

13. Han Q, Bagheri N, Bradshaw EM, Hafler DA, Lauffenburger DA, Love JC. Polyfunctional responses by human T cells result from sequential release of cytokines. Proc Natl Acad Sci U S A. 2012; 109(5):1607-1612.

14. Yao S, Huang D, Chen CY, et al. Differentiation, distribution and gammadelta $\mathrm{T}$ cell-driven regulation of IL-22-producing $\mathrm{T}$ cells in tuberculosis. PLoS Pathog. 2010;6(2):e1000789.

15. Li B, Rossman MD, Imir T, et al. Disease-specific changes in gammadelta $\mathrm{T}$ cell repertoire and function in patients with pulmonary tuberculosis. J Immunol. 1996;157(9):4222-4229.

16. Montamat-Sicotte DJ, Millington KA, Willcox CR, et al. A mycolic acid-specific CD1-restricted $\mathrm{T}$ cell population contributes to acute and memory immune responses in human tuberculosis infection. J Clin Invest. 2011;121(6):2493-2503.

17. Chua WJ, Truscott SM, Eickhoff CS, Blazevic A, Hoft DF, Hansen TH. Polyclonal mucosa-associated invariant $\mathrm{T}$ cells have unique innate functions in bacterial infection. Infect Immun. 2012;80(9): 3256-3267.

18. Gold MC, Cerri S, Smyk-Pearson S, et al. Human mucosal associated invariant $\mathrm{T}$ cells detect bacterially infected cells. PLoS Biol. 2010;8(6):e1000407.

19. Park HD, Guinn KM, Harrell MI, et al. Rv3133c/dosR is a transcription factor that mediates the hypoxic response of Mycobacterium tuberculosis. Mol Microbiol. 2003;48(3):833-843. 
20. Tufariello JM, Mi K, Xu J, et al. Deletion of the Mycobacterium tuberculosis resuscitation-promoting factor Rv1009 gene results in delayed reactivation from chronic tuberculosis. Infect Immun. 2006;74(5):2985-2995.

21. Kana BD, Gordhan BG, Downing KJ, et al. The resuscitation-promoting factors of Mycobacterium tuberculosis are required for virulence and resuscitation from dormancy but are collectively dispensable for growth in vitro. Mol Microbiol. 2008;67(3):672-684.

22. Russell-Goldman E, Xu J, Wang X, Chan J, Tufariello JM. A Mycobacterium tuberculosis Rpf double-knockout strain exhibits profound defects in reactivation from chronic tuberculosis and innate immunity phenotypes. Infect Immun. 2008;76(9):4269-4281.

23. Noss EH, Harding CV, Boom WH. Mycobacterium tuberculosis inhibits MHC class II antigen processing in murine bone marrow macrophages Cell Immunol. 2000;201(1):63-74.

24. Pai RK, Convery M, Hamilton TA, Boom WH, Harding CV. Inhibition of IFN-gamma-induced class II transactivator expression by a $19-\mathrm{kDa}$ lipoprotein from Mycobacterium tuberculosis: a potential mechanism for immune evasion. J Immunol. 2003;171(1):175-184.

25. Boom WH, Canaday DH, Fulton SA, Gehring AJ, Rojas RE, Torres M. Human immunity to $\mathrm{M}$. tuberculosis: $\mathrm{T}$ cell subsets and antigen processing. Tuberculosis (Edinb). 2003;83(1-3):98-106.

26. Sturgill-Koszycki S, Schlesinger PH, Chakraborty P, et al. Lack of acidification in Mycobacterium phagosomes produced by exclusion of the vesicular proton-ATPase. Science. 1994;263(5147):678-681.

27. Pethe K, Swenson DL, Alonso S, Anderson J, Wang C, Russell DG. Isolation of Mycobacterium tuberculosis mutants defective in the arrest of phagosome maturation. Proc Natl Acad Sci USA. 2004 101(37):13642-13647.

28. Rohde K, Yates RM, Purdy GE, Russell DG. Mycobacterium tuberculosis and the environment within the phagosome. Immunol Rev. 2007;219:37-54.

29. Ting LM, Kim AC, Cattamanchi A, Ernst JD. Mycobacterium tuberculosis inhibits IFN-gamma transcriptional responses without inhibiting activation of STAT1. J Immunol. 1999;163(7):3898-3906.

30. Kincaid EZ, Ernst JD. Mycobacterium tuberculosis exerts gene-selective inhibition of transcriptional responses to IFN-gamma without inhibiting STAT1 function. J Immunol. 2003;171(4):2042-2049.

31. Nagabhushanam V, Solache A, Ting LM, Escaron CJ, Zhang JY, Ernst JD. Innate inhibition of adaptive immunity: Mycobacterium tuberculosis-induced IL-6 inhibits macrophage responses to IFNgamma. J Immunol. 2003;171(9):4750-4757.

32. Fortune SM, Solache A, Jaeger A, et al. Mycobacterium tuberculosis inhibits macrophage responses to IFN-gamma through myeloid differentiation factor 88-dependent and -independent mechanisms. J Immunol. 2004;172(10):6272-6280.

33. Banaiee N, Kincaid EZ, Buchwald U, Jacobs WR, Jr., Ernst JD. Potent inhibition of macrophage responses to IFN-gamma by live virulent Mycobacterium tuberculosis is independent of mature mycobacterial lipoproteins but dependent on TLR2. J Immunol. 2006;176(5):3019-3027.

34. Benson SA, Ernst JD. TLR2-dependent inhibition of macrophage responses to IFN-gamma is mediated by distinct, gene-specific mechanisms. PLoS One. 2009;4(7):e6329.

35. Wang P, Wang L, Zhang W, et al. Immunotherapeutic efficacy of recombinant Mycobacterium smegmatis expressing Ag85B-ESAT6 fusion protein against persistent tuberculosis infection in mice. Hum Vaccin Immunother. 2014;10(1):150-158.

36. Yang XY, Chen QF, Li YP, Wu SM. Mycobacterium vaccae as adjuvant therapy to anti-tuberculosis chemotherapy in never-treated tuberculosis patients: a meta-analysis. PLoS One. 2011;6(9):e23826.

37. Yang S, Li F, Jia S, et al. Early secreted antigen ESAT-6 of Mycobacterium Tuberculosis promotes apoptosis of macrophages via targeting the microRNA155-SOCS1 interaction. Cell Physiol Biochem. 2015;35(4):1276-1288.

38. Van Rhijn I, Moody DB. CD1 and mycobacterial lipids activate human T cells. Immunol Rev. 2015;264(1):138-153.
39. Dey B, Dey RJ, Cheung LS, et al. A bacterial cyclic dinucleotide activates the cytosolic surveillance pathway and mediates innate resistance to tuberculosis. Nat Med. 2015;21(4):401-406.

40. Johnson JL, Kamya RM, Okwera A, et al. Randomized controlled trial of Mycobacterium vaccae immunotherapy in non-human immunodeficiency virus-infected Ugandan adults with newly diagnosed pulmonary tuberculosis. The Uganda-Case Western Reserve University Research Collaboration. J Infect Dis. 2000;181(4):1304-1312.

41. Johnson JL, Nunn AJ, Fourie PB, et al. Effect of Mycobacterium vaccae (SRL172) immunotherapy on radiographic healing in tuberculosis. Int J Tuberc Lung Dis. 2004;8(11):1348-1354.

42. Butov DA, Efremenko YV, Prihoda ND, et al. Randomized, placebocontrolled Phase II trial of heat-killed Mycobacterium vaccae (Immodulon batch) formulated as an oral pill (V7). Immunotherapy. 2013;5(10):1047-1054.

43. Gupta A, Ahmad FJ, Ahmad F, et al. Efficacy of Mycobacterium indicus pranii immunotherapy as an adjunct to chemotherapy for tuberculosis and underlying immune responses in the lung. PLoS One. 2012;7(7):e39215.

44. Cardona PJ, Amat I, Gordillo S, et al. Immunotherapy with fragmented Mycobacterium tuberculosis cells increases the effectiveness of chemotherapy against a chronical infection in a murine model of tuberculosis. Vaccine. 2005;23(11):1393-1398.

45. Vilaplana C, Gil O, Caceres N, Pinto S, Diaz J, Cardona PJ. Prophylactic effect of a therapeutic vaccine against TB based on fragments of Mycobacterium tuberculosis. PLoS One. 2011;6(5):e20404.

46. Vilaplana C, Montane E, Pinto S, et al. Double-blind, randomized, placebo-controlled Phase I Clinical Trial of the therapeutical antituberculous vaccine RUTI. Vaccine. 2010;28(4):1106-1116.

47. Nell AS, D'Lom E, Bouic P, et al. Safety, tolerability, and immunogenicity of the novel antituberculous vaccine RUTI: randomized, placebocontrolled phase II clinical trial in patients with latent tuberculosis infection. PLoS One. 2014;9(2):e89612.

48. Lowrie DB, Silva CL. Enhancement of immunocompetence in tuberculosis by DNA vaccination. Vaccine. 2000;18(16):1712-1716.

49. Okada M, Kita Y, Nakajima T, et al. Novel prophylactic vaccine using a prime-boost method and hemagglutinating virus of Japan-envelope against tuberculosis. Clin Dev Immunol. 2011;2011:549281.

50. Tanghe A, D'Souza S, Rosseels V, et al. Improved immunogenicity and protective efficacy of a tuberculosis DNA vaccine encoding Ag85 by protein boosting. Infect Immun. 2001;69(5):3041-3047.

51. Derrick SC, Yang AL, Morris SL. A polyvalent DNA vaccine expressing an ESAT6-Ag85B fusion protein protects mice against a primary infection with Mycobacterium tuberculosis and boosts BCG-induced protective immunity. Vaccine. 2004;23(6):780-788.

52. Okada M, Kita Y, Nakajima T, et al. Novel therapeutic vaccine: granulysin and new DNA vaccine against tuberculosis. Hum Vaccin. 2011; 7 Suppl:60-67.

53. Herzog EL, Chai L, Krause DS. Plasticity of marrow-derived stem cells. Blood. 2003;102(10):3483-3493.

54. Skrahin A, Ahmed RK, Ferrara G, et al. Autologous mesenchymal stromal cell infusion as adjunct treatment in patients with multidrug and extensively drug-resistant tuberculosis: an open-label phase 1 safety trial. Lancet Respir Med. 2014;2(2):108-122.

55. Hogan BL, Yingling JM. Epithelial/mesenchymal interactions and branching morphogenesis of the lung. Curr Opin Genet Dev. 1998;8(4):481-486.

56. Sabatini F, Petecchia L, Tavian M, Jodon de Villeroche V, Rossi GA, Brouty-Boye D. Human bronchial fibroblasts exhibit a mesenchymal stem cell phenotype and multilineage differentiating potentialities. Lab Invest. 2005;85(8):962-971.

57. Tropea KA, Leder E, Aslam M, et al. Bronchioalveolar stem cells increase after mesenchymal stromal cell treatment in a mouse model of bronchopulmonary dysplasia. Am J Physiol Lung Cell Mol Physiol. 2012;302(9):L829-L837.

58. Sinclair K, Yerkovich ST, Chambers DC. Mesenchymal stem cells and the lung. Respirology. 2013;18(3):397-411. 
59. Joshi L, Chelluri LK, Gaddam S. Mesenchymal Stromal cell therapy in MDR/XDR tuberculosis: a concise review. Arch Immunol Ther Exp (Warsz). 2015;63(6):427-433.

60. Batdelger D, Dandii D, Jirathitikal V, Bourinbaiar AS. Open-label trial of therapeutic immunization with oral V-5 Immunitor (V5) vaccine in patients with chronic hepatitis C. Vaccine. 2008;26(22):2733-2737.

61. Butov DA, Pashkov YN, Stepanenko AL, et al. Phase IIb randomized trial of adjunct immunotherapy in patients with first-diagnosed tuberculosis, relapsed and multi-drug-resistant (MDR) TB. J Immune Based Ther Vaccines. 2011;9:3.

62. Arjanova OV, Prihoda ND, Yurchenko LV, et al. Adjunct oral immunotherapy in patients with re-treated, multidrug-resistant or HIV-coinfected TB. Immunotherapy. 2011;3(2):181-191.

63. Butov DA, Efremenko YV, Prihoda ND, et al. Adjunct immune therapy of first-diagnosed TB, relapsed TB, treatment-failed TB, multidrugresistant TB and TB/HIV. Immunotherapy. 2012;4(7):687-695.

64. Jiao X, Lo-Man R, Guermonprez P, et al. Dendritic cells are host cells for mycobacteria in vivo that trigger innate and acquired immunity. J Immunol. 2002;168(3):1294-1301.

65. Flesch I, Kaufmann SH. Mycobacterial growth inhibition by interferongamma-activated bone marrow macrophages and differential susceptibility among strains of Mycobacterium tuberculosis. J Immunol. 1987;138(12):4408-4413.

66. Feng CG, Bean AG, Hooi H, Briscoe H, Britton WJ. Increase in gamma interferon-secreting CD8(+), as well as CD4(+), T cells in lungs following aerosol infection with Mycobacterium tuberculosis. Infect Immun. 1999;67(7):3242-3247.

67. Condos R, Rom WN, Schluger NW. Treatment of multidrug-resistant pulmonary tuberculosis with interferon-gamma via aerosol. Lancet. 1997;349(9064):1513-1515.

68. Giosue S, Casarini M, Ameglio F, et al. Aerosolized interferon-alpha treatment in patients with multi-drug-resistant pulmonary tuberculosis. Eur Cytokine Netw. 2000;11(1):99-104.

69. Koh WJ, Kwon OJ, Suh GY, et al. Six-month therapy with aerosolized interferon-gamma for refractory multidrug-resistant pulmonary tuberculosis. J Korean Med Sci. 2004;19(2):167-171.

70. Balu S, Reljic R, Lewis MJ, et al. A novel human IgA monoclonal antibody protects against tuberculosis. J Immunol. 2011;186(5): 3113-3119.

71. Johnson BJ, Bekker LG, Rickman R, et al. rhuIL-2 adjunctive therapy in multidrug resistant tuberculosis: a comparison of two treatment regimens and placebo. Tuber Lung Dis. 1997;78(3-4):195-203.

72. Johnson JL, Ssekasanvu E, Okwera A, et al. Randomized trial of adjunctive interleukin-2 in adults with pulmonary tuberculosis. Am J Respir Crit Care Med. 2003;168(2):185-191.

73. Shen H, Min R, Tan Q, et al. The beneficial effects of adjunctive recombinant human interleukin-2 for multidrug resistant tuberculosis. Arch Med Sci. 2015;11(3):584-590.

74. Chen CY, Yao S, Huang D, et al. Phosphoantigen/IL2 expansion and differentiation of Vgamma2Vdelta2 $\mathrm{T}$ cells increase resistance to tuberculosis in nonhuman primates. PLoS Pathog. 2013;9(8): e1003501.

75. Fallahi-Sichani M, Flynn JL, Linderman JJ, Kirschner DE. Differential risk of tuberculosis reactivation among anti-TNF therapies is due to drug binding kinetics and permeability. J Immunol. 2012;188(7): 3169-3178.

76. Wallis RS, Kyambadde P, Johnson JL, et al. A study of the safety, immunology, virology, and microbiology of adjunctive etanercept in HIV-1-associated tuberculosis. AIDS. 2004;18(2):257-264.

77. Hernandez-Pando R, Orozco-Esteves H, Maldonado HA, et al. A combination of a transforming growth factor-beta antagonist and an inhibitor of cyclooxygenase is an effective treatment for murine pulmonary tuberculosis. Clin Exp Immunol. 2006;144(2):264-272.

78. Roy E, Brennan J, Jolles S, Lowrie DB. Beneficial effect of antiinterleukin-4 antibody when administered in a murine model of tuberculosis infection. Tuberculosis (Edinb). 2008;88(3):197-202.
79. Vordermeier HM, Venkataprasad N, Harris DP, Ivanyi J. Increase of tuberculous infection in the organs of B cell-deficient mice. Clin Exp Immunol. 1996;106(2):312-316.

80. Maglione PJ, Xu J, Chan J. B cells moderate inflammatory progression and enhance bacterial containment upon pulmonary challenge with Mycobacterium tuberculosis. J Immunol. 2007;178(11):7222-7234.

81. Lopez Y, Yero D, Falero-Diaz G, et al. Induction of a protective response with an IgA monoclonal antibody against Mycobacterium tuberculosis $16 \mathrm{kDa}$ protein in a model of progressive pulmonary infection. Int J Med Microbiol. 2009;299(6):447-452.

82. Roy E, Stavropoulos E, Brennan J, et al. Therapeutic efficacy of highdose intravenous immunoglobulin in Mycobacterium tuberculosis infection in mice. Infect Immun. 2005;73(9):6101-6109.

83. Hamasur B, Haile M, Pawlowski A, Schroder U, Kallenius G, Svenson SB. A mycobacterial lipoarabinomannan specific monoclonal antibody and its $\mathrm{F}(\mathrm{ab}$ ') fragment prolong survival of mice infected with Mycobacterium tuberculosis. Clin Exp Immunol. 2004;138(1):30-38.

84. de Valliere S, Abate G, Blazevic A, Heuertz RM, Hoft DF. Enhancement of innate and cell-mediated immunity by antimycobacterial antibodies. Infect Immun. 2005;73(10):6711-6720.

85. Mayanja-Kizza H, Jones-Lopez E, Okwera A, et al. Immunoadjuvant prednisolone therapy for HIV-associated tuberculosis: a phase 2 clinical trial in Uganda. J Infect Dis. 2005;191(6):856-865.

86. Chatterjee S, Nutman TB. Helminth-induced immune regulation: implications for immune responses to tuberculosis. PLoS Pathog. 2015;11(1):e1004582

87. Abate E, Belayneh M, Idh J, et al. Asymptomatic helminth infection in active tuberculosis is associated with increased regulatory and Th-2 responses and a lower sputum smear positivity. PLoS Negl Trop Dis. 2015;9(8):e0003994.

88. Singh MM, Kumar P, Malaviya AN, Kumar R. Levamisole as an adjunct in the treatment of pulmonary tuberculosis. Am Rev Respir Dis. 1981;123(3):277-279.

89. Abate E, Elias D, Getachew A, et al. Effects of albendazole on the clinical outcome and immunological responses in helminth co-infected tuberculosis patients: a double blind randomised clinical trial. Int $J$ Parasitol. 2015;45(2-3):133-140.

90. Liu PT, Stenger S, Li H, et al. Toll-like receptor triggering of a vitamin D-mediated human antimicrobial response. Science. 2006;311(5768):1770-1773.

91. Selvaraj P, Harishankar M, Afsal K. Vitamin D: Immuno-modulation and tuberculosis treatment. Can J Physiol Pharmacol. 2015;93(5):377-384.

92. Bruns H, Stegelmann F, Fabri M, et al. Abelson tyrosine kinase controls phagosomal acidification required for killing of Mycobacterium tuberculosis in human macrophages. J Immunol. 2012;189(8):4069-4078.

93. Napier RJ, Rafi W, Cheruvu M, et al. Imatinib-sensitive tyrosine kinases regulate mycobacterial pathogenesis and represent therapeutic targets against tuberculosis. Cell Host Microbe. 2011;10(5):475-485.

94. Go SI, Lee WS, Lee GW, et al. Nilotinib-induced interstitial lung disease. Int J Hematol. 2013;98(3):361-365.

95. Lee NR, Jang JW, Kim HS, Yhim HY. Imatinib mesylate-induced interstitial lung disease in a patient with prior history of Mycobacterium tuberculosis infection. Korean J Intern Med. 2015;30(4):550-553.

96. Singhal A, Jie L, Kumar P, et al. Metformin as adjunct antituberculosis therapy. Sci Transl Med. 2014;6(263):263ra159.

97. Parihar SP, Guler R, Khutlang R, et al. Statin therapy reduces the mycobacterium tuberculosis burden in human macrophages and in mice by enhancing autophagy and phagosome maturation. J Infect Dis. 2014;209(5):754-763.

98. Stanley SA, Barczak AK, Silvis MR, et al. Identification of host-targeted small molecules that restrict intracellular Mycobacterium tuberculosis growth. PLoS Pathog. 2014;10(2):e1003946.

99. Vilaplana C, Marzo E, Tapia G, Diaz J, Garcia V, Cardona PJ. Ibuprofen therapy resulted in significantly decreased tissue bacillary loads and increased survival in a new murine experimental model of active tuberculosis. J Infect Dis. 2013;208(2):199-202. 
100. Byrne ST, Denkin SM, Zhang Y. Aspirin and ibuprofen enhance pyrazinamide treatment of murine tuberculosis. J Antimicrob Chemother. 2007;59(2):313-316.

101. Mayer-Barber KD, Andrade BB, Oland SD, et al. Host-directed therapy of tuberculosis based on interleukin-1 and type I interferon crosstalk. Nature. 2014;511(7507):99-103.

102. Maiga M, Ammerman NC, Maiga MC, et al. Adjuvant host-directed therapy with types 3 and 5 but not type 4 phosphodiesterase inhibitors shortens the duration of tuberculosis treatment. J Infect Dis. 2013; 208(3):512-519.

103. Subbian S, Tsenova L, O'Brien P, et al. Phosphodiesterase-4 inhibition combined with isoniazid treatment of rabbits with pulmonary tuberculosis reduces macrophage activation and lung pathology. Am J Pathol. 2011;179(1):289-301.

104. Chen L, Wang J, Zganiacz A, Xing Z. Single intranasal mucosal Mycobacterium bovis BCG vaccination confers improved protection compared to subcutaneous vaccination against pulmonary tuberculosis. Infect Immun. 2004;72(1):238-246.
105. Santosuosso M, Zhang X, McCormick S, Wang J, Hitt M, Xing Z Mechanisms of mucosal and parenteral tuberculosis vaccinations: adenoviral-based mucosal immunization preferentially elicits sustained accumulation of immune protective CD4 and CD8 T cells within the airway lumen. J Immunol 2005;174(12):7986-7994.

106. Santosuosso M, McCormick S, Zhang X, Zganiacz A, Xing Z. Intranasal boosting with an adenovirus-vectored vaccine markedly enhances protection by parenteral Mycobacterium bovis BCG immunization against pulmonary tuberculosis. Infect Immun. 2006;74(8):4634-4643.

107. Jeyanathan M, Heriazon A, Xing Z. Airway luminal T cells: a newcomer on the stage of TB vaccination strategies. Trends Immunol. 2010;31(7):247-252.

\section{Publish your work in this journal}

ImmunoTargets and Therapy is an international, peer-reviewed open access journal focusing on the immunological basis of diseases, potential targets for immune based therapy and treatment protocols employed to improve patient management Basic immunology and physiology of the immune system in health, and disease will be also covered. In addition, the journal will focus on the impact of manage-

\section{Dovepress}

ment programs and new therapeutic agents and protocols on patient perspectives such as quality of life, adherence and satisfaction. The manuscript management system is completely online and includes a very quick and fair peer-review system, which is all easy to use. Visit http://www.dovepress.com/testimonials.php to read real quotes from published authors.

Submit your manuscript here: http://www.dovepress.com/immunotargets-and-therapy-journal 